\title{
Study on the Construction of Teaching System Combined With Digital Design and Manufacturing Technology
}

\author{
He Miao \\ NanChang Institute of Science \& Technology
}

\begin{abstract}
In order to meet the social demand for talents of digital design and manufacturing technology, promote teaching reform with engineering practice, explore a teaching system based on digital technology and centered on students, this paper understands the informatization connotation of manufacturing industry based on the integrated teaching platform of PDM digital design and manufacturing technology so as to plan teaching system for practical courses of engineering subjects, practical teaching procedure as well as management mode. Besides, each separated technology involved in the development of digital products should be combined with related courses in the major of mechanical design and manufacturing as well as automation by strengthening comprehensive practice with the digital development of new products as the main stream so as to establish a new cultivation mode suitable for digital design and manufacturing environment.
\end{abstract}

Keywords-digital design and manufacture; practical teaching; talent cultivation

\section{INTRODUCTION}

Mechanical engineering is an ancient subject developed with human's civilization. As early as in the Warring States Period, China has owned a high level of mechanical engineering. Mechanical engineering in the early stage mainly relied on animals, wind and water. Later, steam engine and electronic technology were invented, which brought overturning change to manufacturing for the first time. The invention of computer as well as the popularity of Internet have changed people's way of communication thoroughly, which changed the manufacturing mode and operational mode of manufacturing industry again. Americans have carried out systematic study and prospect on the manufacturing of next generation in the 1990s to draw a sketch of manufacturing in the Information Age with many new ideas and new theories, which have been widely spread all over the world.
The rapid development of information technology has promoted the development of digital design and manufacturing technologies. The modern manufacturing enterprises are purchasing lots of digital equipment, managing system as well as designing and researching software, during which there is a serious conflict between digital tools and traditional manufacturing mode, and thus professionals in digital design and manufacture are in urgent demand. Higher education in colleges and universities are seriously lack behind practical demand since the students of these majors are of poor qualities for enterprises' need. In this paper, it explores the combination of CAD/CAM/CAE/PLM technologies and traditional subjects of mechanical engineering so as to establish a teaching platform integrated with digital design and manufacturing. Thus, students can experience the work mode of modern manufacture during practice. By this way, students can be cultivated into representatives of new productive forces to meet the need of modern manufacturing industry.

In order to adapt to the development of new technologies of manufacturing industry and meet the social demand for talents with digital technologies, it is advocated in the paper that traditional curriculum settings should be reformed with integration, supplement and optimization of scattered and repeated digital manufacturing courses by systematically establishing an educational system for digital design and manufacturing technologies of mechanical engineering majors. Meanwhile, new curriculum setting and cultivation mode should be explored. 


\section{DNC TECHNOLOGY}

DNC is called distributed numerical control, which is based on digital controlling technology, computer technology and communication technology. It integrates numerically-controlled machine tool with upper-controlled computer to realize a centralized control and management with information exchange. $\mathrm{DNC}$ is a bond to realize the integration of CAD/CAM and computer auxiliary production and management system, and it is also another form of automatic mechanical processing. Meanwhile, it is a new way to realize information integration, functions integration and equipment integration in modern workshops.
As early as in 1980, IS02806 defined DNC as direct numerical control, which is a one-to-one management mode. NC programs are stored in one storer, which is connected to multiple numerically-controlled machine tools by DNC system. Data will be transmitted to corresponding machine tools immediately by system after receiving requests. Later, with the development of digital technology, the concept of DNC was updated by IS02806 as distributed control. From the direct control to distributed control and to now, DNC technology has experience 30 years of development. Its four development steps are shown in table 1 as follows.

TABLE 1 DEVELOPMENT PROCESS OF DNC TECHNOLOGY

\begin{tabular}{|c|c|}
\hline Periods & Main functions \\
\hline The first stage before 2004 & $\begin{array}{l}\text { The stage of direct numerical control, during } \\
\text { which the main function is to solve the problem of } \\
\text { networking and program transmission between } \\
\text { numerically-controlled machine tool and } \mathrm{NC} \\
\text { program storer. }\end{array}$ \\
\hline The second stage From 2004 to 2007 & $\begin{array}{l}\text { The stage of distributed numerical control, during } \\
\text { which the main function is to realize NC program } \\
\text { management and fake edition based on network } \\
\text { transmission. That is, workers, machine tools, } \\
\text { engineers, managers and servers that are in } \\
\text { different places are assembled in one system with } \\
\text { integrated management by a set of DNC system. } \\
\text { Network transmission, program management and } \\
\text { fake edition are three functional models of DNC } \\
\text { necessarily. }\end{array}$ \\
\hline The third stage From 2007 to 2010 & $\begin{array}{l}\text { The stage of DNC of broad sense. Besides all } \\
\text { functions mentioned in the second stage, it also } \\
\text { needs to collect yearly data and monitor machine } \\
\text { tools. }\end{array}$ \\
\hline The fourth stage From 2010 to now & $\begin{array}{l}\text { The stage of digital workshop with integrated } \\
\text { solutions to meet demand of high-end customers, } \\
\text { during which DNC technology is treated on the } \\
\text { whole. DNC is the basis and precondition of } \\
\text { implementing MES, and it is the basis and } \\
\text { component of digital workshop. }\end{array}$ \\
\hline
\end{tabular}




\section{MAIN CONTENTS RELATED TO DEVELOPMENT TECHNOLOGIES OF DIGITAL PRODUCTS}

The development technologies of digital products have combined with related advanced technologies during modern design and manufacturing, which can be divided into three models like digital design, digital manufacturing and digital management. Respective technologies of each model are displayed as follows in Fig .1.

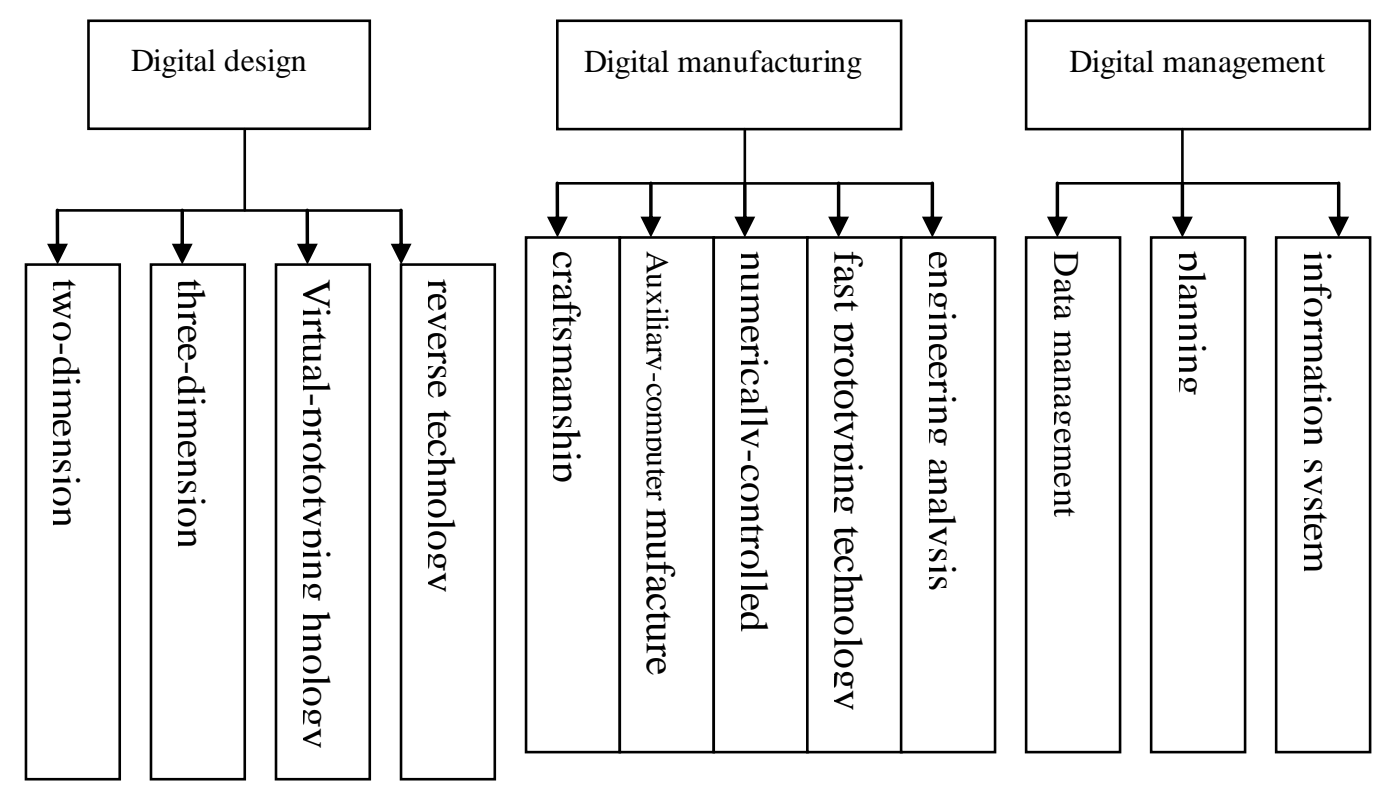

Figure 1. Digital design technology related unit

\section{CONCLUSION}

It is a creative study for the reformation of higher engineering education to establish a teaching platform combined PDM digital design and manufacturing, and it is also an effective means to cultivate application talents of undergraduate degree. Surrounded by the establishment of teaching platform for digital design and manufacturing integration, the paper has conducted work and studies on the following aspects.

Establish a teaching platform for digital design and manufacturing integration based on PDM. Complete a customized PDM system according to the teaching demand of digital design and manufacturing.

By taking digital design and manufacturing in Zhong Qian Beng as an example and simulating enterprises' environment to conduct practical teaching activities, the paper studies and conducts the whole process of three-dimension digital design and manufacturing on the teaching platform.

Practice teaching is an important platform to cultivate students' innovative awarenss and practicability. A systematic practice course system has been established by reforming the teaching of digital design and manufacturing so that many disciplines have been combined together, which indicates a comprehensive and interactive property. The students' initiative has been greatly motivated with strong purpose, and meanwhile students' dominant role as well as teacher's guiding effect have also been fully embodied with better comprehensive abilities of studying and applying knowledge.

\section{REFERENCE}

[1] $\mathrm{Hu}, \mathrm{Y} H \& X \mathrm{M} H \mathrm{Hu} \& \mathrm{C}$ Zheng \&H J Lv. Implementation of Management Model for Manufacturing Information Based to PDM,[J]. Key Engineering Materials,2010(458) :258-264. 
[2] Higgins\&Amy . Is this possible: PDM and ERP capabilities in one program [J] Machine Design. 2002.

[3] Y 14.41-2003.Digital product definition data practices [S]. New York: ASME, 2003:234-240

[4] DEF STAN 05-10 part 2.Digital product definition information [S].London: UK,2006.

[5] Penoyer J A\&Burnett G\&Fawcett D J et al. Knowledge Based Product LifeCycle Systems: Principles of Integration of KBE and C3P. Computer- AidedDesign, 2000,32:311-320.

[6] Kim C Y\&N Kim\&Yv Kim. Internet-based concurrent engineering: an interactive $3 \mathrm{~d}$ system with markup [J]. Proceedings of the ASME Computers in Engineering Conference, Atlanta, 1998(08): 68-70.

[7] Weidlich D\&L Cser\&TPoIzin .Vulaal reality approaches for immersivedesign $[\mathrm{J}]$.International Journal on Interactive Design and Manufacturing 2009, 3(2) : 103-108.
[8] CHE J L\&GONG Y P\&JIN T\&ET al. Development of an integrated CAD/CAM system for shoe last [C].2005 IEEE International Conference on Mechatronics and Automations(1-4): 1107-1110

[9] Beard Tom. Look What's Happened To DNC [J]. Modern machine shop , 1992, 6:12

[10] Jamieson R. Direct slicing of CAD models for rapid prototyping [j].Rapid Prototyping Journal, 1995(2) : 4-10.

[11] 3-5Dimitrov D\&Schreve K\&de Beer N. Advances in Three Dimensional Printing-State of the Art and Future Perspectives[C]. 10th European Forum on Rapid Prototyping and Manufacturing. Paris, France Sep, 2004

[12] MeClelland D C .Testing for competence rather than for intelligence [J],Ameriean ps ychologist, 1973(28): 1-14. 